\title{
Smoke Hazard Assessment Model Based on Fire Dynamics Simulator and FED Model
}

\author{
Nianfeng Li, Shang Zhou*, Zhiguo Xiao, Yifei Zhao \\ School of Computer Science and Technology, Changchun University of Science and Technology, Changchun, China \\ Email: *3390428508@qq.com
}

How to cite this paper: Li, N.F., Zhou, S., Xiao, Z.G. and Zhao, Y.F. (2020) Smoke Hazard Assessment Model Based on Fire Dynamics Simulator and FED Model. Journal of Computer and Communications, $\mathbf{8}$, 81-93.

https://doi.org/10.4236/jcc.2020.89007

Received: August 24, 2020

Accepted: September 19, 2020

Published: September 22, 2020

Copyright (C) 2020 by author(s) and Scientific Research Publishing Inc. This work is licensed under the Creative Commons Attribution International License (CC BY 4.0).

http://creativecommons.org/licenses/by/4.0/

\begin{abstract}
Smoke is the main cause of fire death. In order to minimize the potential danger of smoke hazard, a rational VR based fire training simulator should fully consider all aspects of smoke hazard. In the simulator, the visualization of data based on FDS (Fire Dynamics Simulator) and FED fire dynamic data and volume rendering is further optimized, which can be effectively and quickly applied to virtual fire protection. In addition, a comprehensive smoke hazard assessment model based on FED and FED is established to assess the IHD value of different paths, which represents the safety of different paths, and can be used for evacuation or rescue in virtual training. Taking the case of campus fire drill as an experiment, the research shows the accuracy and effectiveness of smoke assessment based on FDS and FED model. The road force with the highest safety can be selected through the comprehensive model. So the assessment model is proved to be valuable.
\end{abstract}

\section{Keywords}

Smoke Hazard, Smoke Visualization, Integrated Smoke Assessment Model, FDS, FED

\section{Introduction}

Fires are one of the most common disasters in cities, often resulting in serious economic losses and even more human deaths. According to the international report [1], smoke is the cause of fire, and $1 / 3$ of the number of deaths from building fires in China each year. Evacuation paths and smoke reduction play a vital role in many fire accidents. Therefore, minimizing the effects of smog is a key issue that effectively reduces fire-related injuries and evacuates deaths and rescues. Through the process of evacuation or rescue training, inexperienced firefighters and even the general public can conduct fire drills and improve the 
actual situation of smoke hazards through practice [2]. However, due to high public opinion and high economic costs, high risks (such as toxic gases and uncontrolled fires) can lead to casualties; it is not practical to conduct actual fire training for inexperienced firefighters and the general public. Compared with such potential hazards, the somato sensory and VR simulation system can provide safe, low-cost, appropriate learning plans and repeated training environments, evacuation and rescue procedures. On this basis, the VR simulation system contains smoke hazards worthy of further study. It is mainly to simulate people's ability of safe fire evacuation and rescue training in case of fire. This VR fire simulation has two key technical challenges: 1) visualizing an accurate and realistic smoke environment for virtual training purposes; 2) assessing smoke hazards, which can be used for evacuation or rescue processes under different paths. Simulate to determine the safest road.

For challenge (1), based on the visualization of fire data, smoke will greatly hinder people's vision during evacuation, which makes it more difficult to search the exit path, thus hindering escape. Firefighters and the general public encounter the same situation, and their vision is limited. Therefore, accurate smoke visualization plays an important role in virtual effective evacuation and rescue. In order to realize the reasonable visualization of smoke and accurately determine the necessary smoke characteristics (such as its distribution and density), in the development, it is necessary to optimize the VR simulator as much as possible, which will use some computational fluid dynamics content. Computational Fluid Dynamics [2] [3] has the corresponding output capacity and can obtain the smoke data quite accurately; in addition, volume rendering is a common visualization method, which has been widely used High fidelity visualization of Computational Fluid Dynamics data. In view of the above, Computational Fluid Dynamics data and volume rendering will be used to develop accurate and effective smoke visualization technology in this study.

For challenge (2), a comprehensive assessment model for smoke is a necessary condition to help people identify correctly in danger, looking for the safest route to evacuate or rescue. The smog hazard is mainly due to its toxicity and heat. The toxic effects of smoke, the FED, are described in the assessment model and are among the most widely used indices in the world. Based on the FED evaluation index, the thermal hazard of smog is proposed. It is obvious that toxicity and heat both seriously affect the relative safety of the evacuation path. However, the comprehensive evaluation considers that the models of these two hazards have not been widely applied.

The followings are some national standards involved in fire risk assessment. Industry standards and local standards are shown in Table 1.

The current situation of fire risk assessment standards in China shall be implemented from August 1 of that year. The standard defines the steps and procedures of fire risk assessment, and provides standardized calculation methods for technical indicators such as the occurrence probability, consequence severity and uncertainty of fire events [4]. 
Table 1. Some industry and local standards of fire risk assessment in China [3].

\begin{tabular}{|c|c|c|c|c|}
\hline Standard No. & Standard name & Publishing Department & $\begin{array}{c}\text { Implementation } \\
\text { Date }\end{array}$ & Status \\
\hline DB21/T 2186-2013 & $\begin{array}{l}\text { Fire safety assessment } \\
\text { of high risk fire units }\end{array}$ & $\begin{array}{c}\text { Liaoning Provincial Bureau } \\
\text { of quality and technical } \\
\text { supervision }\end{array}$ & 2014-01-20 & active \\
\hline DB37/T 2409-2013 & $\begin{array}{l}\text { Fire safety assessment } \\
\text { rules for high risk fire } \\
\text { units }\end{array}$ & $\begin{array}{c}\text { Shandong Provincial Bureau } \\
\text { of quality and technical } \\
\text { supervision }\end{array}$ & $2013-11-20$ & active \\
\hline DB62/T 2475-2014 & $\begin{array}{c}\text { Fire safety assessment } \\
\text { standard for fire high } \\
\text { risk units }\end{array}$ & $\begin{array}{c}\text { Gansu Provincial Bureau of } \\
\text { quality and technical } \\
\text { supervision }\end{array}$ & $2014-07-26$ & active \\
\hline DB61/T 1164-2015 & $\begin{array}{l}\text { Fire safety assessment } \\
\text { standard for fire high } \\
\text { risk units }\end{array}$ & $\begin{array}{l}\text { Bureau of quality and } \\
\text { technical supervision of } \\
\text { Guangxi Zhuang } \\
\text { Autonomous Region }\end{array}$ & $2015-06-10$ & active \\
\hline DB61/T 926-2014 & $\begin{array}{l}\text { Fire safety assessment } \\
\text { rules for high risk fire } \\
\text { units }\end{array}$ & $\begin{array}{c}\text { Shanxi Provincial Bureau of } \\
\text { quality and technical } \\
\text { supervision }\end{array}$ & 2015-01-10 & active \\
\hline DB63/T 1380-2015 & $\begin{array}{l}\text { Guidelines for fire } \\
\text { safety assessment of } \\
\text { fire risk units }\end{array}$ & $\begin{array}{l}\text { Qinghai Provincial Bureau of } \\
\text { quality and technical } \\
\text { supervision }\end{array}$ & 2015-03-15 & active \\
\hline DB64/T 1021-2014 & $\begin{array}{l}\text { Fire safety assessment } \\
\text { rules for high risk fire } \\
\text { units }\end{array}$ & $\begin{array}{l}\text { Ningxia Hui Autonomous } \\
\text { Region Bureau of quality and } \\
\text { technical supervision }\end{array}$ & 2012-02-01 & active \\
\hline GBT 27921-2011 & $\begin{array}{l}\text { Risk management; } \\
\text { Risk assessment } \\
\text { technology }\end{array}$ & $\begin{array}{c}\text { National Quality } \\
\text { Supervision, inspection and } \\
\text { quarantine }\end{array}$ & 2014-12-03 & active \\
\hline GA/T 1369-2016 & $\begin{array}{l}\text { Crowded place; } \\
\text { Fire safety assessment } \\
\text { guide }\end{array}$ & Ministry of public security & 2017-03-01 & active \\
\hline
\end{tabular}

In this simulator, based on fire dynamic data and volume visualization technology, rendering is a smoke evolution process in a VR scene designed for vivid and accurate display. In addition, the safest evacuation or rescue route is determined, and a smoke hazard assessment model is established on this basis. Finally, set up two fire scenes, a school and a subway station, for investigation and experimentation.

\section{Smoke Visualization}

In this study, smoke visualization is an important prerequisite for the assessment of smoke hazard. Only the clear visualization of smoke can ensure the accuracy of subsequent research evaluation. For this reason, the data model based on FDS fire dynamic data and volume rendering is optimized. Ensure that the smoke process is simulated in real time and accurately, as shown in Figure 1.

The main purpose of the data model based on FDS fire dynamic data and volume rendering is to solve the typical fire problem in fire safety engineering. It 


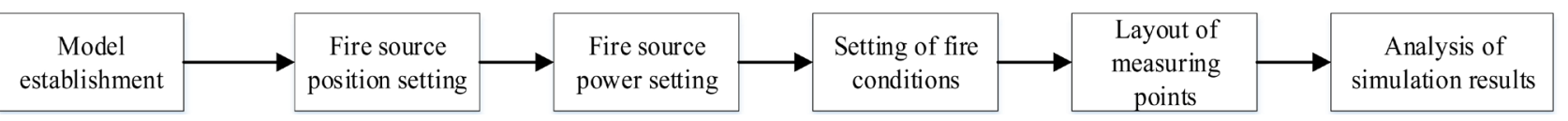

Figure 1. FDS fire simulation process.

can process both dynamic data and static data, and display the data in two or three dimensions [5]. It shows in Table 2.

Volume rendering is often used as an important method for depicting smoke visualization, suitable for using FDS grid data. FDS divides space into discrete volumes through a grid system with specific thermo physical properties. In addition, the time step in the FDS and the soot density in each grid, the duration of the simulation can be automatically componentized [6]. Create a VR environment after the grid in the FDS. The opacity value of the voxel can be normalized to specify the soot density value in the corresponding grid, as shown in Figure 2.

That is, it is used to accurately represent the low visibility caused by smoke, and the opacity value of each voxel is equal to the voxel ratio, that is, the relationship between the corresponding soot density and the maximum soot density. During the rendering process, the opacity value of the voxel grid is dynamically adjusted according to the value of the soot density in each time range. With this method, the real state of the visualization of the smoke can be realistically described in the VR scene.

The number and time of the mesh extracted in the FDS simulation, such a large amount of data will lead to slow data query, real-time smoke visualization becomes a big technical problem, and the rendering efficiency is inefficient, eliminating the user's poor experience in interaction. The problem. In order to reduce the burden of data storage, speed up rendering efficiency, and simplify the multi-level data model of smoke, a visualization of smoke has been proposed. For

Table 2. FDS parameter setting.

\begin{tabular}{cl}
\hline Parameter & \multicolumn{1}{c}{ Content } \\
\hline FDS input & $\begin{array}{l}\text { Grid, coordinate system, building size, fire source (shape, size, location), obstacle, } \\
\text { fire detector, boundary condition, slice information, environmental temperature, } \\
\text { pumidity, pressure, wind speed, simulation time, etc. }\end{array}$ \\
FDS output & $\begin{array}{l}\text { Smoke particle opacity, visibility, smoke particle flow speed, scene temperature, } \\
\text { parameters }\end{array}$ \\
& $\begin{array}{l}\text { scene pressure, scene density, fire source heat release rate, combustion product } \\
\text { concentration, etc. }\end{array}$ \\
\hline
\end{tabular}
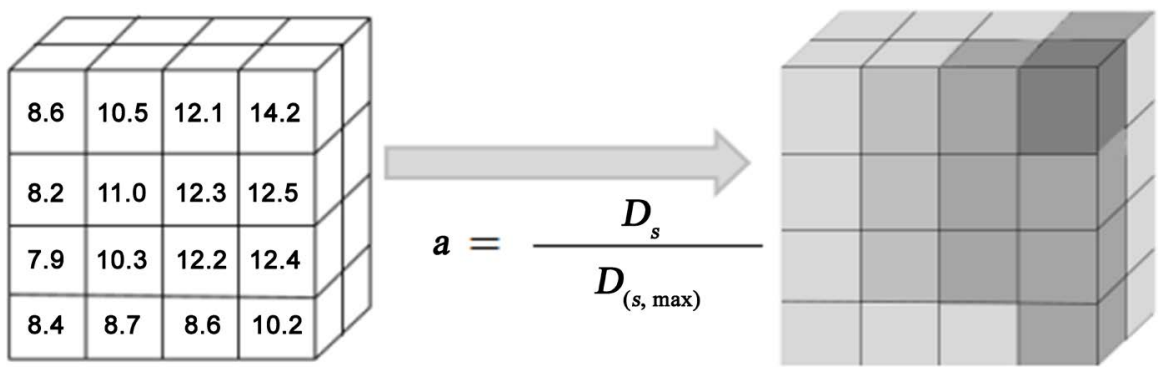

Figure 2. Converting from soot density to opacity in a voxel grid. 
grids with a zero soot density, the corresponding voxel grid will not be rendered, so the data model based on FDS fire dynamics and volume rendering reduces the amount of rendering effort. Under the same conditions, the efficiency of the mathematical model proposed in the visualization is 60 FPS beyond, which confirms the validity of the proposed data model and effectively simulates the real-time process of VR smoke evolution.

\section{Smoke Hazard Assessment}

The main hazards of smoke include heat and heat. One of the evaluation indexes of smoke toxicity is the comprehensive effect of various gases. Fed is an important toxicity model parameter for 30 minute exposure. On the basis of fed, combined with 6-gas model [7], the comprehensive evaluation is carried out. According to the previous modeling idea of face-to-face object software engineering methodology, the comprehensive smoke evaluation based on fed and FDS is optimized The model needs to go through three steps: model building, model review and model effect evaluation. The specific steps are shown in Figure 3.

First, for the problem based on the FED integrated smoke assessment model, implement relevant demand acquisition and analysis to determine the target of the model to be established. Second, based on the multi-view modeling approach, establish the concept based on the FED integrated smoke assessment model. Model, architecture model and implementation model, and establish the

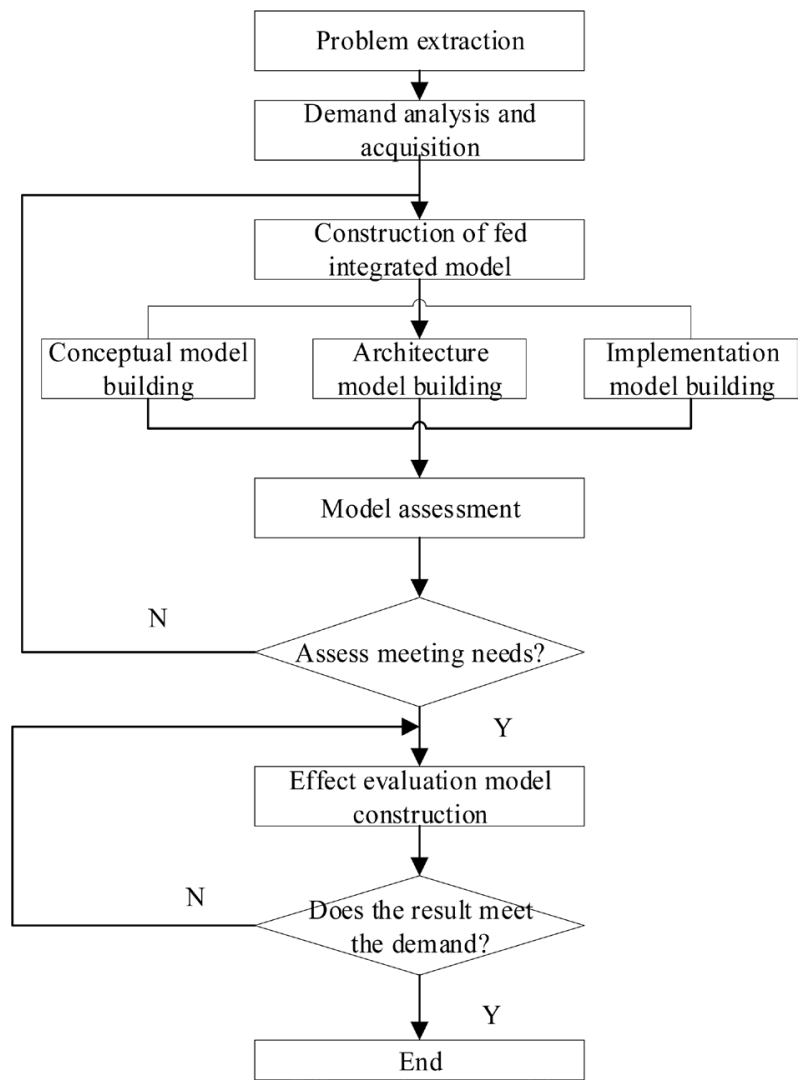

Figure 3. The construction process of the FED comprehensive evaluation model. 
relationship between the three, provide relevant data for the study of effect evaluation; third, evaluate the established model, the purpose of this is to ensure the accuracy of the model, Because the wrong model is bound to affect the construction of the effect evaluation model and the evaluation effect.

\subsection{Conceptual Model Based on FED Integrated Smoke Assessment Model}

Based on the FED, a conceptual model of the corresponding integrated smoke assessment is constructed, combined with the known 6-Gas model [7] [8] for visualization and evaluation of the synthesis of six gases (i.e. $\mathrm{CO}, \mathrm{CO}_{2}, \mathrm{HCN}, \mathrm{O}_{2}$, $\mathrm{HCl}$ and $\mathrm{HBr}$ ). Toxicity values appear in the smoke, as shown in Equation (1):

$$
\mathrm{FED}_{6-\mathrm{Gas}}=\frac{\mathrm{m}[\mathrm{CO}]}{\left[\mathrm{CO}_{2}\right]-b}+\frac{[\mathrm{HCN}]}{\mathrm{LC}_{50, \mathrm{HCN}}}+\frac{21-\left[\mathrm{O}_{2}\right]}{21-\mathrm{LC}_{50, \mathrm{O} 2}}+\frac{[\mathrm{HCL}]}{\mathrm{LC}_{50, \mathrm{HCl}}}+\frac{[\mathrm{HBr}]}{\mathrm{LC}_{50, \mathrm{HBr}}}
$$

The numerical symbols in brackets represent the average concentration exposure period within 30 minutes. These atmospheric concentrations can be obtained through FDS model, and the results are accurate within $20 \%$ of the experimental measurement [8] [9]. The higher the FED 6-gas is, the higher the integration degree is, the higher the toxicity of smoke is. When FED $=1.0$, the toxicity of smoke is related to the probability of death. A small part of the heat obtained during the period can be determined by the total radiation convection. The heat flow is caused by radiant heat. Before that, the data of temperature $\mathrm{T}$ and radiant flux $\mathrm{Q}$ at specific location are needed. The higher the heat of FED is, the greater the thermal hazard is. When FED heat $=1.0$, radiant heat and heat are close to the threshold of human life, so people are in danger of death. Toxicity and heat have different injury mechanisms, which may be fatal if exposed for a long time. Based on the above discussion on the separate assessment of smoke hazard, i.e. integrated hazard dose (IHD), the calculation is as follows (2):

$$
\mathrm{IHD}=\max \left(\mathrm{FED}_{6 \text {-Gas, }} \text { FED heat }\right)
$$

\subsection{Model Framework of FED Comprehensive Smoke Assessment}

Based on the conceptual model of FED integrated smoke assessment model, the model framework of FED integrated smoke assessment is proposed, as shown in Figure 4.

The FED framework model focuses on the process of effect evaluation, focusing on the relationship between the main elements of smoke evaluation activities and the environment, as well as the constraints that the model should meet, reflecting the different perspectives of smoke effect evaluation research. The elements in the FED architecture model can respectively represent service and processing, data and association relationships, where Association elements are responsible for combining different parts of the model.

\subsection{Implementation of FED Integrated Smoke Assessment Model}

The implementation model of FED comprehensive smoke assessment can be 
described by UML (Unified Modeling Language) class diagram model to express the specific elements, the relationship between the elements, the design constraints that the model should meet, etc., as shown in Figure 5.

\subsection{Application of Comprehensive Smoke Assessment Model Based on FED}

Based on the comprehensive smoke assessment model based on fed and FDS, it is an important application direction and the most critical step to determine whether the evacuation or rescue path is safe, and it is also the most important problem in virtual evacuation training. Since the path of evacuation or rescue is

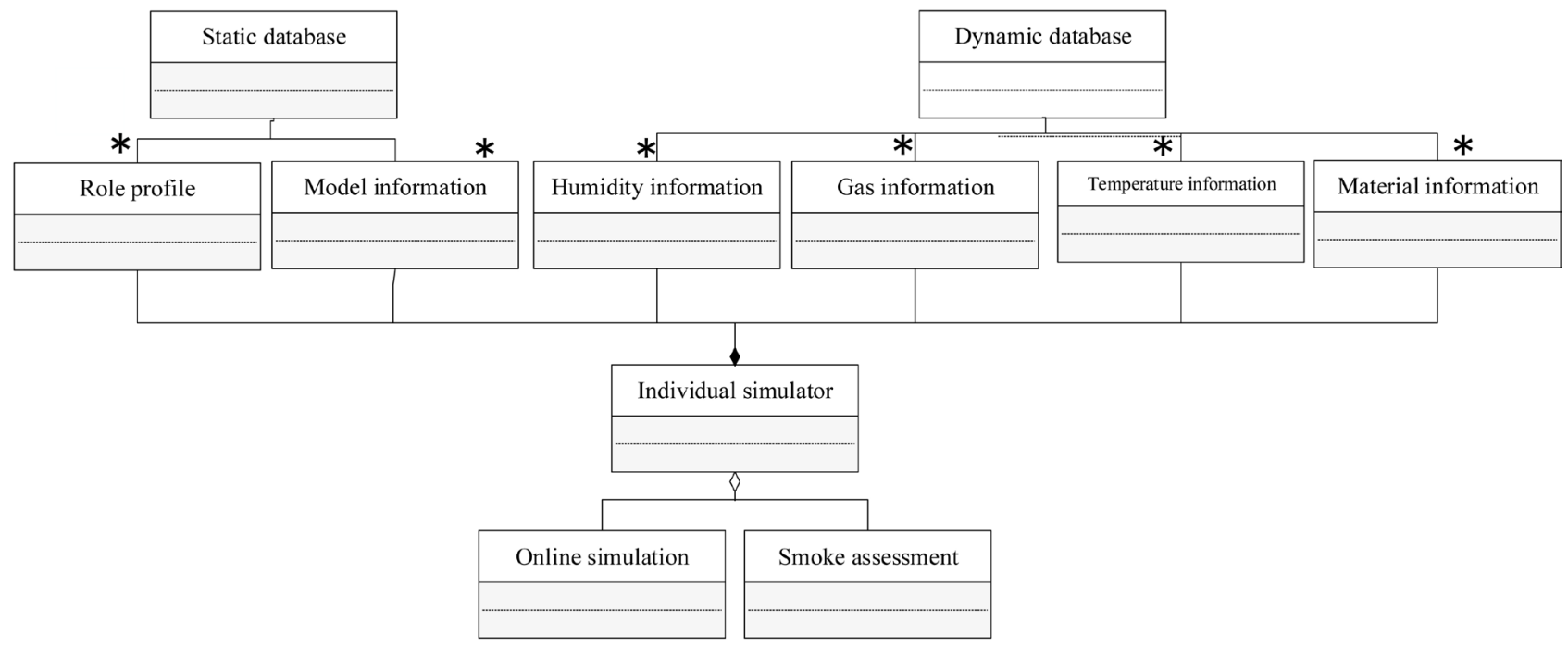

Note: $\triangle$ in the figure represents the inheritance relationship, $\bullet$ represents the composition relationship, * represents the "many" party in the 1-to-many relationship, the same below.

Figure 4. Architecture model based on FED comprehensive evaluation.

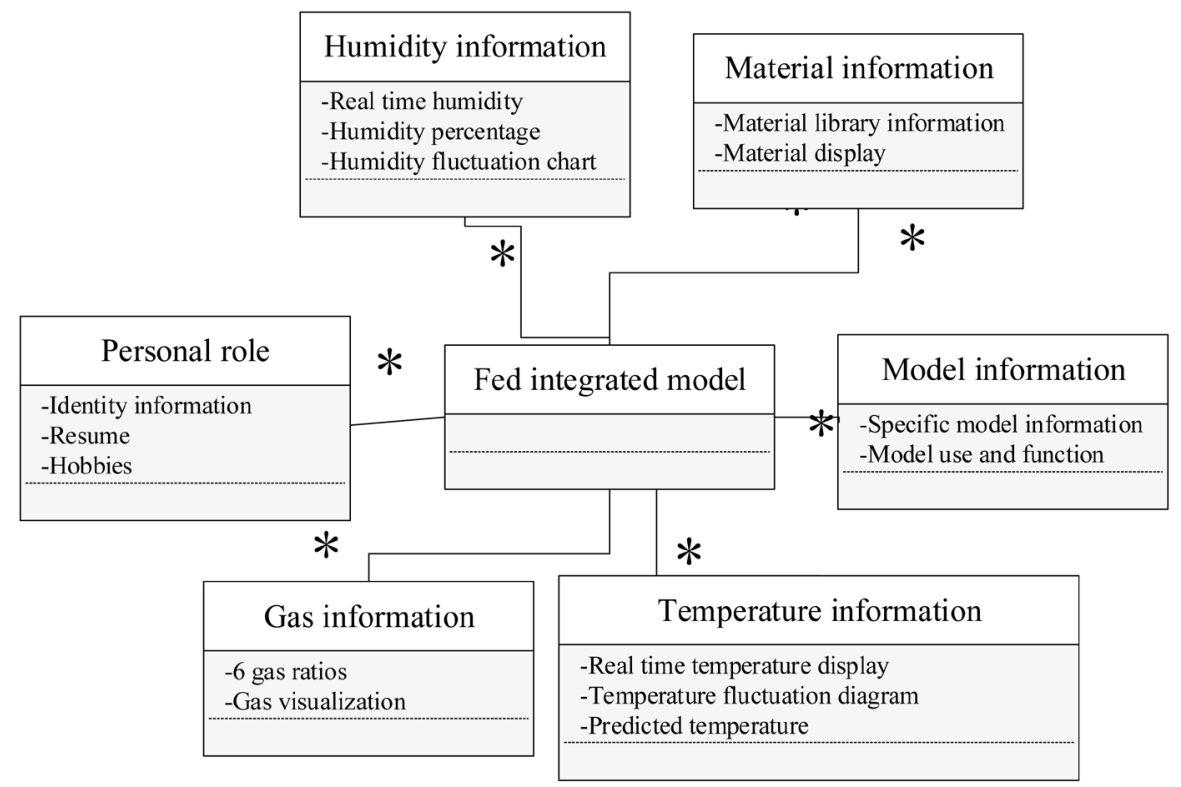

Figure 5. The implementation of fed integrated model. 
a specific time-space curve, that is, a specific three-dimensional space, the comprehensive hazard index of different paths can be evaluated by integrating the IHD on the corresponding curve.

The route of evacuation or rescue is determined by the operation of trainees, which can be planned in varying degrees according to the training content, not by any clear function. In this study, fire dynamic simulation and VR scene are based on the corresponding grid. Among them, the fire dynamics data, such as temperature, atmospheric concentration, etc., need to analyze the radiation flux, time step and other basic information of trainees in each grid, which can be obtained by FDS calculation. Therefore, the comprehensive hazard index in the path can be defined as IHD path. In the training of VR training simulator, due to the uneven distribution of smoke, different evacuation operations or rescue paths have different IHD path values. The lower the IHD, the safer the evacuation path. Therefore, VR training simulator based on IHD path can help students analyze and find the safest evacuation or rescue path.

\section{VR training Simulator}

Based on the above smoke visualization and integrated assessment of smoke hazards, the VR training simulator is supported by fire dynamic data. The whole VR training system has four main steps, as shown in Figure 6.

1) VR model and FDS model are created according to the same building information.

2) The fire dynamics simulation is obtained by FDS and its results, especially, the data of soot density is stored effectively, and the smoke is visualized by the multi-level data model.

3) Voxel grid can accurately visualize the evolution process of smoke to provide

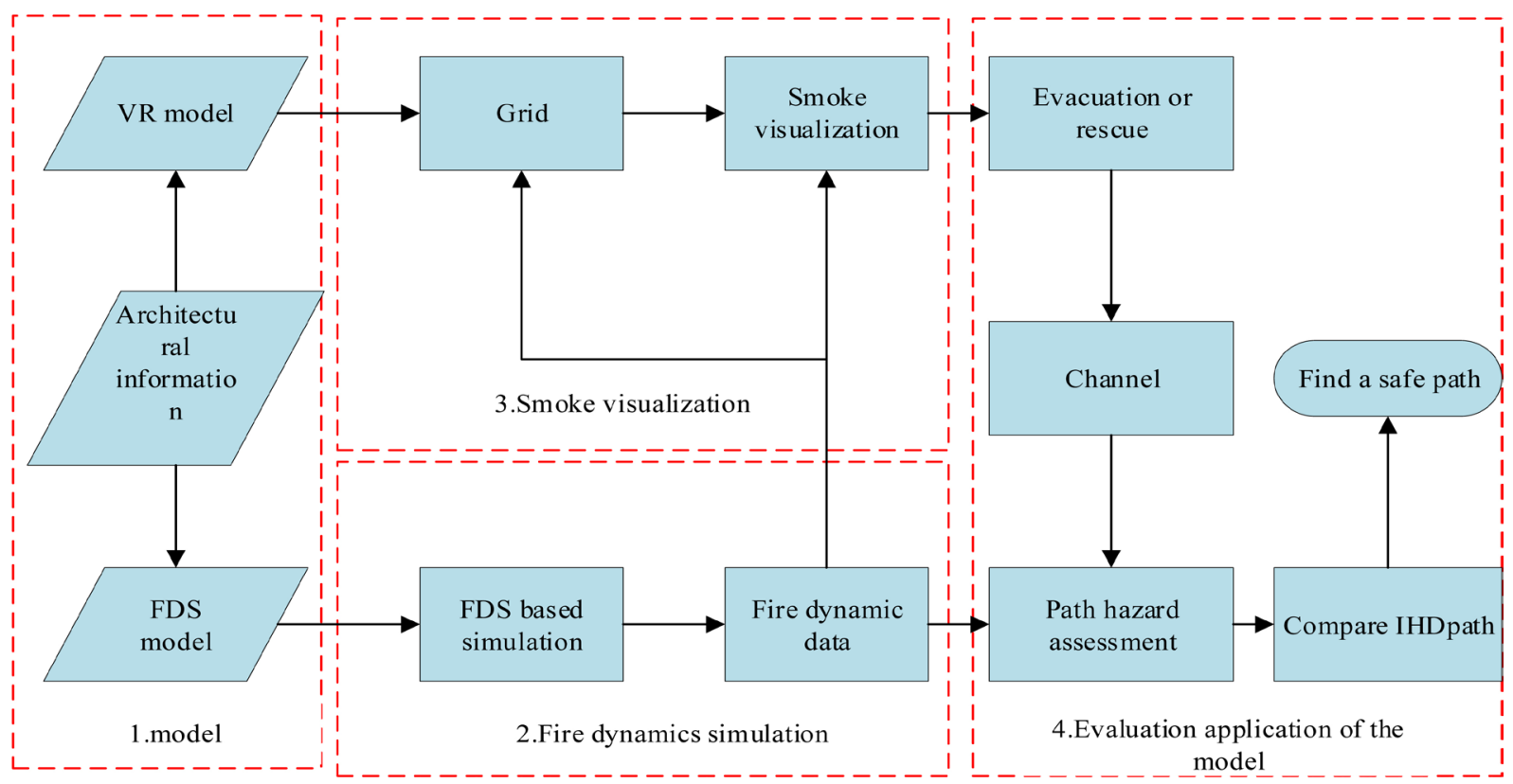

Figure 6. Flow chart of proposed fire virtual training simulator. 
realistic fire scene;

4) VR training simulator is used to simulate training in real fire scene and choose different rescue paths.

Subsequently, the hazards of smoke are evaluated based on the values of IHD paths. The smaller the IHD path, the safer the corresponding path [10].

By comparing the values of IHD paths, it is determined that the path with the smallest IHD path is the safest. For the participants in the training, loading the pre calculated fire scene, i.e. the VR model and fire dynamic data of FDS [11], is the first step of applying the simulator, which can observe the smoke propagation information in the virtual scene. As a campus, subway, building or tunnel, each can simulate the real fire environment, and can move in any direction in the virtual scene.

\section{Experiment and Discussion Based on Fire Simulator}

\subsection{Campus Fire Rescue}

Based on the FDS fire dynamic data and volume rendering, the IHD values of different positions are calculated to evaluate the corresponding risk of the path, in order to help students and teachers choose a safer way to escape. The scene of the fire is a four story teaching building, in which the top floor is on fire. The school plan is shown in Figure 7.

In this case, a student is trapped in a nearby classroom fire source, and firefighters can use two ways to rescue: a 30.5-meter-long path 1 through the nearby corridor fire source; and a path 2 is 43.1 -meter-long, but not near the fire source. With instructions from the simulator, firefighters will be able to determine which path is faster and safer. In FDS, the response of wood and plastic to fire evolution is simulated by combustion, and the whole simulation time is 10 minutes. Based on the CFD data of FDS [12], accurate virtual smoke creates an environment for rescue training, as shown in Figure 8.

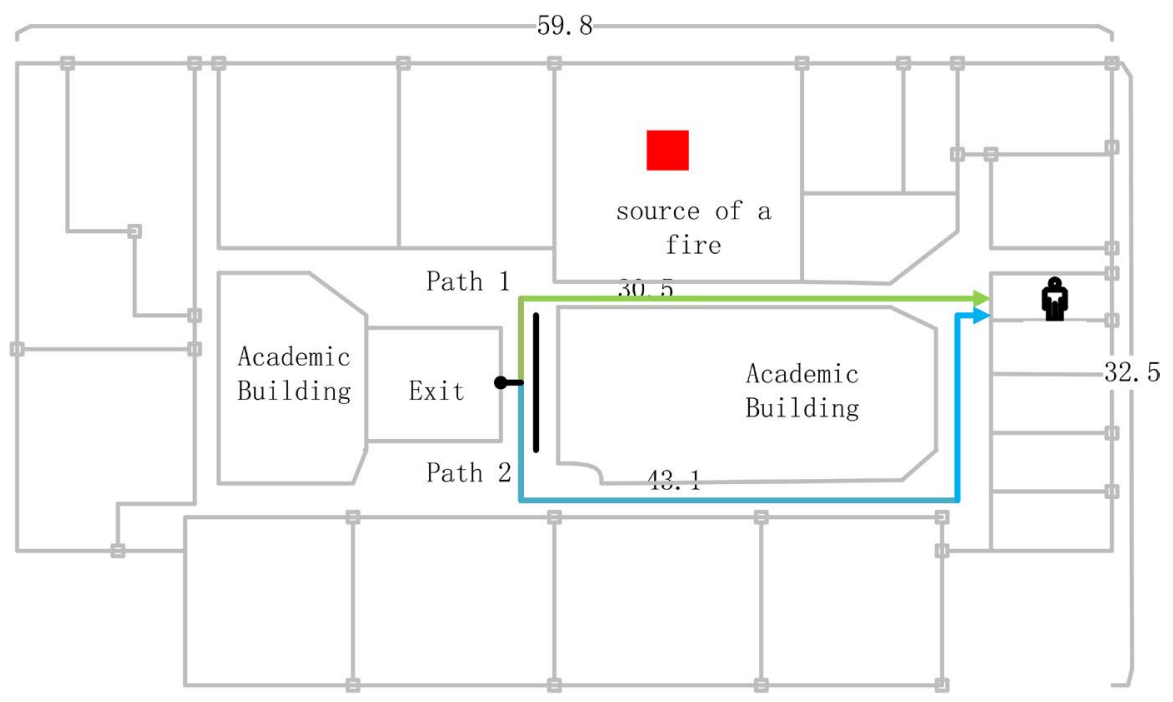

Figure 7. Fire scenario on campus (unit: $\mathrm{m}$ ). 


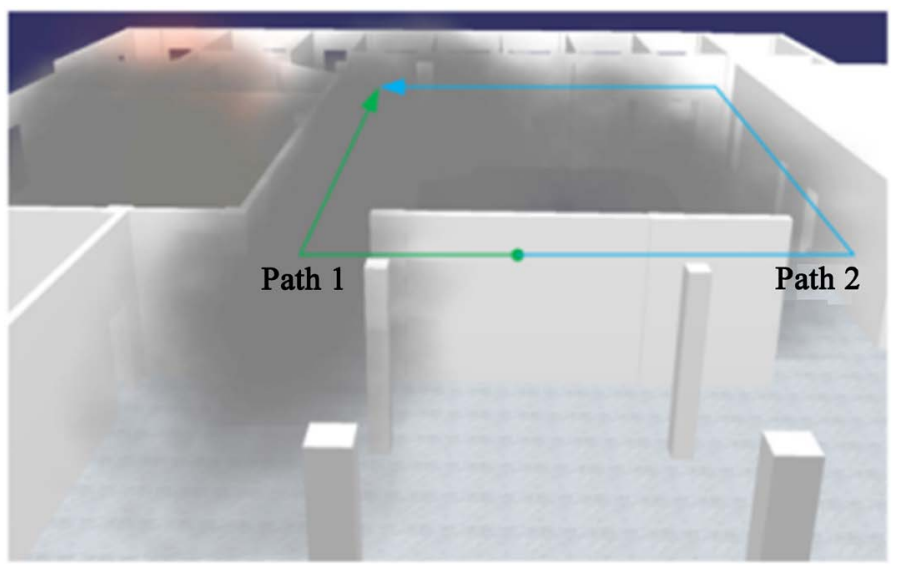

Figure 8. Virtual smoke environment for rescue training.

\subsection{Discussion on Experiment}

According to the above experimental design ideas, the following discussion is carried out. The virtual environment provides a visual comparison method for firefighters, showing that the smoke in path 1 is much heavier than that in path 2. According to the above experiments, the following data are obtained, as shown in the Table 3.

As a result, firefighters are likely to think Route 1 is dangerous. This smoke distribution is shown in Figure 8, which is consistent with the FDS results, and the rendering efficiency can reach 60 FPS, which provides an effective environment for students to be active. During training, the driving speed range is 0.8 to $2.0 \mathrm{M} / \mathrm{s}$. Results virtual training showed that the rescue time of path 1 and 2 was 30 seconds and 36.5 seconds respectively. Due to the limited visibility of smoke, the travel speed of path 1 is slightly slower than that of path 2, which leads to no significant difference in rescue time. However, the difference in smoke hazards, i.e. the IHD path, is significant in both paths, as shown in Figure 9.

As the smaller the IHD path is, the safer the corresponding path is. According to the IHD value, draw the corresponding overall security trend chart. According to the chart, compare the security at different times, as shown in Figure 10 .

The IHD path is 0.25 in path 1 , while the IHD path in path 2 is only 0.09 , almost one-third of that in path 1 . Given that path 2 is almost at the same time as path 1 but is more secure, path 2 is considered a better option for a. When the virtual simulation is finished, the evacuation path selected by smoke assessment will be presented to trainees, which will increase the awareness of hazard characteristicsp [13] [14], so as to improve the awareness in the process of safe evacuation. After several training, trainees will finally learn to choose the safest path and rescue in a given fire scene. Such training experience will reduce the smoke hazards in the actual fire process [15]. In order to conduct effective evacuation training, the simulator should have high accuracy and good interaction performance. 
Table 3. Experimental data sheet.

\begin{tabular}{lcccccccccccc}
\hline Time & & $\mathbf{1}$ & $\mathbf{2}$ & $\mathbf{5}$ & $\mathbf{8}$ & $\mathbf{1 1}$ & $\mathbf{1 4}$ & $\mathbf{1 7}$ & $\mathbf{2 0}$ & $\mathbf{2 3}$ & $\mathbf{2 6}$ & $\mathbf{2 9}$ \\
\hline \multirow{2}{*}{ Path 1 } & IHD & 0 & 0.03 & 0.05 & 0.06 & 0.08 & 0.13 & 0.14 & 0.15 & 0.16 & 0.18 & 0.25 \\
& $\begin{array}{c}\text { Security } \\
\text { trend }\end{array}$ & 3.5 & 3.4 & 3.0 & 2.8 & 2.7 & 2.3 & 2.1 & 1.7 & 1.35 & 1.3 & 1.3 \\
& IHD & 0 & 0.02 & 0.03 & 0.04 & 0.05 & 0.055 & 0.06 & 0.07 & 0.09 & 0.10 & 0.10 \\
Path 2 & $\begin{array}{c}\text { Security } \\
\text { trend }\end{array}$ & 3.5 & 3.46 & 3.3 & 3.1 & 3.05 & 3.02 & 3.0 & 2.9 & 2.8 & 2.7 & 2.5 \\
\hline
\end{tabular}

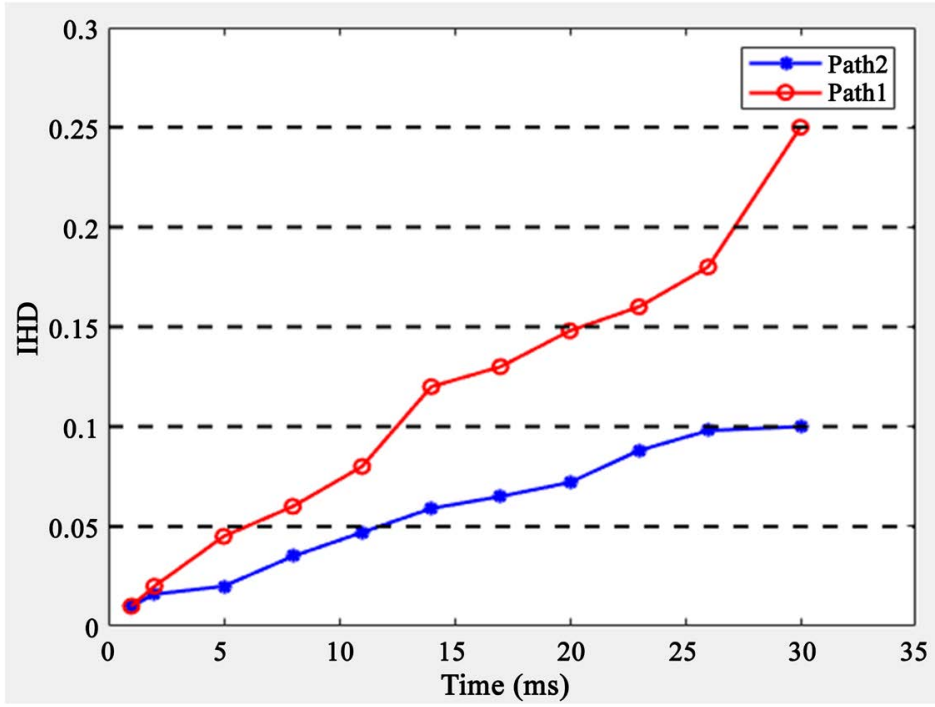

Figure 9. IHD values in two evacuation routes.

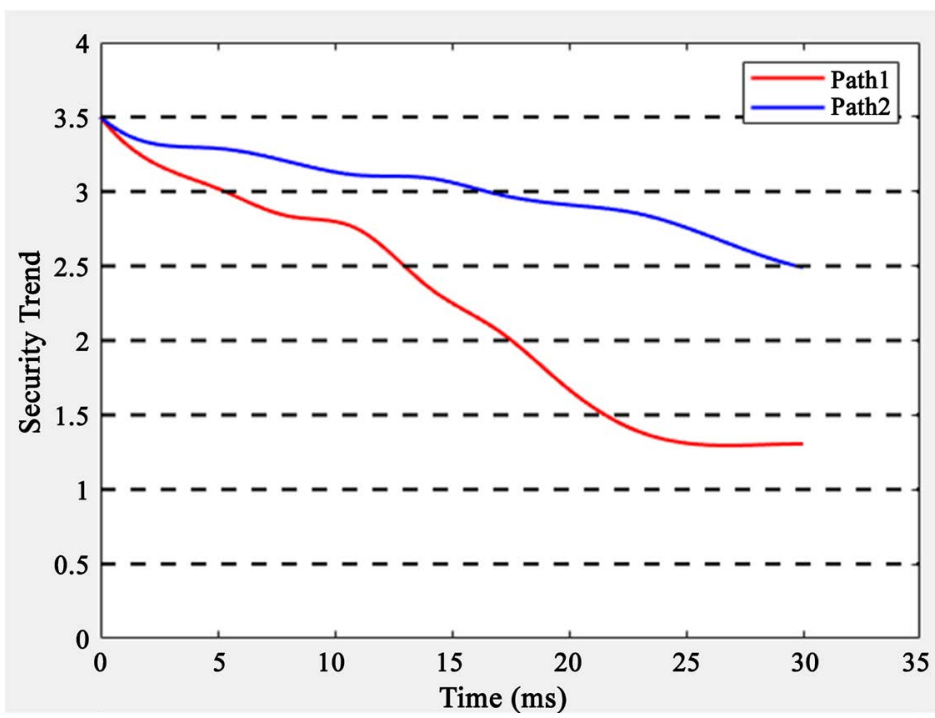

Figure 10. Security trend.

\section{Summary and Outlook}

In the virtual fire scene training, the dynamic data and volume rendering based on FDS can be applied to smoke visualization. After special design, this method 
provides a realistic simulated smoke environment for users, which is close to the real virtual fire environment. Secondly, the comprehensive smoke assessment model based on fed and FDS integrates the toxicity and heat hazards into smoke. It is an evaluation model for evacuation or rescue route in virtual reality, i.e. IHD route. The smaller the IHD path is, the greater the correlation is, and the safer the corresponding path is. On the contrary, the larger the IHD path is, the less the correlation is, and the more dangerous the corresponding path is. Therefore, the IHD path can be used to evaluate a more secure virtual training path.

Based on the integrated smoke assessment model of smoke visualization, fed and FDS, a VR fire training simulator with smoke hazard assessment is constructed. According to the existing conditions, taking the case of campus fire protection as the background, it is proved that the simulator can enable trainees to experience more real fire scenes, and determine the safest route for evacuation or rescue according to the IHD value, so as to help students learn how to reduce smoke hazards as much as possible, so as to achieve the learning effect of the system.

Based on the virtual reality technology and the related theory of fire education, this study takes the fire object as the target of the system development, constructs the factor model of the use effectiveness of the virtual reality fire training system, and finally tests the model through the quantitative empirical research. At the same time, due to the limitations of research time and researchers' ability, this study mainly has the following shortcomings:

1) Although the training function of the evaluation model designed in this study is more complete, but the evaluation method designed is less, and there are errors, so it should be evaluated several times in a proper range.

2) In the stage of empirical research, there are fewer samples of research objects, which may have errors and expand the sample of research objects. In this study, a student of Computer College of Changchun University is taken as the research object to get the practical effectiveness of the virtual reality fire training system. The sample of the research object is less, and the sample of the research object needs to be expanded for empirical research to test.

\section{Acknowledgements}

This research was supported by Project of the Education Department of Jilin Province (Project No. JJKH20191204KJ and Project No. JJKH20191207KJ) and Jilin Science and Technology Development Plan Project (Project No. 20170204033GX).

\section{Conflicts of Interest}

The authors declare no conflicts of interest regarding the publication of this paper.

\section{References}

[1] Flynn, J.D. (2010) Characteristics of Home Fire Victims. National Fire Protection Association, Quincy. 
[2] Forney, G.P., Madrzykowski, D., McGrattan, K.B. and Sheppard, L. (2003) Understanding Fire and Smoke Flow through Modeling and Visualization. IEEE Computer Graphics and Applications, 23, 6-13. https://doi.org/10.1109/MCG.2003.1210858

[3] Shi, L., Chen, C., Li, X.J., et al. (2019) Underground Space Enhanced Experiential Fire Escape VR System Based on FDS. Chinese Journal of Safety Sciences, 29, 70-75.

[4] Zhang, W.K., Xu, L. and Wang, M.Z. (2019) Numerical Simulation Analysis of Office Building Fire Based on FDS. Journal of Dalian University of Nationalities, 21.

[5] Zhang, Y. (2018) Discussion on Fire Simulation and Application Based on FDS. Science and Information Technology, No. 24, 58-59.

[6] Kaufman, A. (1990) Volume visualization. The Visual Computer, 6, 1. https://doi.org/10.1007/BF01902623

[7] Babrauskas, V., Levin, B.C., Gann, R.G., Paabo, M., Harris Jr., R.H., Peacock, R.D., et al. (1992) Toxic Potency Measurement for Fire Hazard Analysis. Fire Technology, 28, 163-167. https://doi.org/10.1007/BF01857942

[8] Olenick, S.M. and Carpenter, D.J. (2003) An Updated International Survey of Computer Models for Fire and Smoke. Journal of Fire Protection Engineering, 13, 87-110. https://doi.org/10.1177/1042391503013002001

[9] McGrattan, K., McDermott, R., Hostikka, S. and Floyd, J. (2012) Fire Dynamics Simulator (Version 5) Technical Reference Guide. National Institute of Standards and Technology, Baltimore. https://doi.org/10.6028/NIST.SP.1018e6

[10] (2020) FDS Welcomes Inclusion of Oral Health in Early Years Curriculum. British Dental Journal, 229, 81. https://doi.org/10.1038/s41415-020-1970-3

[11] Liu, X., Cai, Z.Y., Ma, S.J., et al. (2019) Numerical Simulation of High Rise Building Fire Based on FDS. Value Engineering, 38, 131-133.

[12] Wang, M.L., Jiao, L.L., Wang, X.H., et al. (2019) Forest Fire Simulation and Rescue System Based on GIS. Information Recording Materials, 20, 144-145.

[13] Guo, S.B. (2020) Status Quo and Countermeasures of Fire Safety in University Libraries. Scientific Consultation (Education and Scientific Research), 9, 103-104.

[14] Karter, M.J. (2011) Fire Loss in the United States during 2010. National Fire Protection Association Fire, Quincy.

[15] Venhola, A., Peletier, R., Laurikainen, E., et al. (2019) The Fornax Deep Survey (FDS) with VST. Astronomy \& Astrophysics, 625, Article No. A143.

https://doi.org/10.1051/0004-6361/201935231 